\title{
A novel heavy-fermion state in $\mathrm{CaCu}_{3} \mathrm{Ru}_{4} \mathrm{O}_{12}$
}

\author{
Wataru Kobayashi $^{1 *}$, Ichiro Terasaki ${ }^{1,2}$, Jun-ichi TAKeya $^{3}$, Ichiro Tsukada ${ }^{3}$ and Yoichi Ando ${ }^{3}$ \\ ${ }^{1}$ Department of Applied Physics, Waseda University, Tokyo 169-8555, Japan \\ ${ }^{2}$ CREST, Japan Science and Technology Agency, Tokyo 108-0075, Japan \\ ${ }^{3}$ Central Research Institute of Electric Power Industry, Tokyo 201-8511, Japan
}

\begin{abstract}
We have measured susceptibility, specific heat, resistivity, and thermopower of $\mathrm{CaCu}_{3} \mathrm{Ti}_{4-x} \mathrm{Ru}_{x} \mathrm{O}_{12}$ and $\mathrm{CaCu}_{3-y} \mathrm{Mn}_{y} \mathrm{Ru}_{4} \mathrm{O}_{12}$, and have found that $\mathrm{CaCu}_{3} \mathrm{Ru}_{4} \mathrm{O}_{12}$ can be regarded as a heavy-fermion oxide in d-electron systems. The Kondo temperature is near 200 $\mathrm{K}$, and the susceptibility $\left(1.4 \times 10^{-3} \mathrm{emu} / \mathrm{Cu} \mathrm{mol}\right)$ and the electron specific heat coefficient $(28$ $\mathrm{mJ} / \mathrm{Cu} \mathrm{molK}^{2}$ ) are moderately enhanced. The resistivity is proportional to $T^{2}$ at low temperatures, and satisfies the Kadowaki-Woods relation. The heavy-fermion state comes from the interaction between the localized moment of $\mathrm{Cu} 3 \mathrm{~d}$ and the conduction electron of $\mathrm{Ru} 4 \mathrm{~d}$. An insulator-metal transition occurs between $x=1.5$ and 4 in $\mathrm{CaCu}_{3} \mathrm{Ti}_{4-x} \mathrm{Ru}_{x} \mathrm{O}_{12}$, which can be regarded as a transition from magnetic insulator to heavy-fermion metal.
\end{abstract}

KEYWORDS: heavy fermion, transition-metal oxide, ordered perovskite

\section{Introduction}

A large family of $\mathrm{AC}_{3} \mathrm{~B}_{4} \mathrm{O}_{12}\left[\mathrm{~A}=\mathrm{Na}^{+}, \mathrm{Cd}^{2+}, \mathrm{Ca}^{2+}\right.$, $\mathrm{Sr}^{2+}, \mathrm{Y}^{3+}, \mathrm{R}^{3+}, \mathrm{Th}^{4+}$ or $\mathrm{U}^{4+}$ ( $\mathrm{R}$; lanthanide). $\mathrm{B}=\mathrm{Mn}^{3+}$, $\mathrm{Fe}^{3+}, \mathrm{Al}^{3+}, \mathrm{Cr}^{3+}, \mathrm{Ti}^{4+}, \mathrm{Mn}^{4+}, \mathrm{Ge}^{4+}, \mathrm{Ru}^{4+}, \mathrm{Ir}^{4+}, \mathrm{Nb}^{5+}$, $\mathrm{Ta}^{5+}$ or $\mathrm{Sb}^{5+} \cdot \mathrm{C}=\mathrm{Cu}^{2+}$ or $\left.\mathrm{Mn}^{3+}\right]$ have an ordered perovskite-type structure in which a Jahn-Teller ion such as $\mathrm{Cu}^{2+}$ or $\mathrm{Mn}^{3+}$ is located in the A site of the perovskite $\mathrm{ABO}_{3}$. They have wide variety of cation compositions, and various substitutions are possible for the A, B and C sites. ${ }^{1}$ Although they were synthesized in 1970's, ${ }^{2,3}$ they had not been studied so much until Subramanian et al. discovered an enormously large dielectric constant of $\mathrm{CaCu}_{3} \mathrm{Ti}_{4} \mathrm{O}_{12}$ in 2000. ${ }^{4}$ Many researchers have investigated an origin of the large dielectric constant, which is still controversial at present. ${ }^{5-8}$ Giant magnetoresistance ${ }^{9}$ and phase separation ${ }^{10}$ in $\mathrm{CaMn}_{3-x} \mathrm{Cu}_{x} \mathrm{Mn}_{4} \mathrm{O}_{12}$ are a second example. We think that these interesting physical properties are related to the peculiar crystal structure, and have studied the transport properties of the $\mathrm{AC}_{3} \mathrm{~B}_{4} \mathrm{O}_{12}$ compounds. ${ }^{8,11,12}$

A heavy-fermion system is a strongly correlated electron system where localized f-electrons interact with conduction electrons through the Kondo effect. In this system, a high and narrow peak appears in the quasiparticle density of states $D$ near the Fermi energy $E_{F}$. The large $D\left(E_{F}\right)$ is reflected in a large susceptibility and electron specific-heat coefficient. $\mathrm{LiV}_{2} \mathrm{O}_{4}$ has been regarded as a typical example of the heavy fermion system in delectron systems. ${ }^{13} \mathrm{In}_{\mathrm{LiV}_{2}} \mathrm{O}_{4}$, however, $\mathrm{V} 3 \mathrm{~d}$ electrons act as conduction electrons and local moments simultaneously. Thus we cannot distinguish the local moment site from the conduction electron site. In this meaning, $\mathrm{LiV}_{2} \mathrm{O}_{4}$ is not equivalent to the f-electron heavy-fermion system.

$\mathrm{CaCu}_{3} \mathrm{Ru}_{4} \mathrm{O}_{12}$ is one of the $\mathrm{AC}_{3} \mathrm{~B}_{4} \mathrm{O}_{12}$-type oxides, and exhibits a good metallic conduction down to $4 \mathrm{~K}$. It shows higher conductivity than $\mathrm{CaRuO}_{3}$ with less tilted $\mathrm{RuO}_{6}$ octahedra, which would be difficult to understand

*E-mail address: kobayashi-wataru@suou.waseda.jp if only the Ru-O network would be conductive. Subramanian and Sleight ${ }^{14}$ proposed "valence degeneracy" for the electronic states of $\mathrm{CaCu}_{3} \mathrm{Ru}_{4} \mathrm{O}_{12}$, where $\mathrm{Cu}^{2+}$ would contribute to the electric conduction. Their explanation was, however, phenomenological, and the microscopic mechanism was not clearly understood. In this paper, we will propose that $\mathrm{CaCu}_{3} \mathrm{Ru}_{4} \mathrm{O}_{12}$ is a novel delectron heavy-fermion system, which is truly equivalent to the f-electron heavy-fermion system in the sense that the local moment $(\mathrm{Cu} 3 \mathrm{~d})$ and the conduction electron $(\mathrm{Ru} 4 \mathrm{~d})$ are clearly distinguished. This is evidenced by the substitution of $\mathrm{Mn}$ for $\mathrm{Cu}$ in $\mathrm{CaCu}_{3-y} \mathrm{Mn}_{y} \mathrm{Ru}_{4} \mathrm{O}_{12}$, where the anomalous impurity effects are observed. We have further found that an insulator-metal transition occurs in $\mathrm{CaCu}_{3} \mathrm{Ti}_{4-x} \mathrm{Ru}_{x} \mathrm{O}_{12}$, which can be regarded as a transition from magnetic insulator to heavy-fermion metal.

\section{Experimentalal}

Polycrystalline samples of $\mathrm{CaCu}_{3} \mathrm{Ti}_{4-x} \mathrm{Ru}_{x} \mathrm{O}_{12}(x=$ 0, 0.5, 1 and 1.5), and $\mathrm{CaCu}_{3-y} \mathrm{Mn}_{y} \mathrm{Ru}_{4} \mathrm{O}_{12}(y=0,0.1$, 0.2 and 0.3 ) were prepared by a solid-state reaction (Note that the sample of $y=0$ is identical to that of $x=4)$. Stoichiometric amounts of $\mathrm{CaCO}_{3}, \mathrm{CuO}, \mathrm{RuO}_{2}, \mathrm{TiO}_{2}$, and $\mathrm{Mn}_{3} \mathrm{O}_{4}$ were mixed, and $\mathrm{CuO}$ flux was added to $\mathrm{CaCu}_{3-y} \mathrm{Mn}_{y} \mathrm{Ru}_{4} \mathrm{O}_{12} \cdot{ }^{15}$ The mixture was calcined in air at $1000-1050{ }^{\circ} \mathrm{C}$ for $20 \mathrm{~h}$ for $\mathrm{CaCu}_{3} \mathrm{Ti}_{4-x} \mathrm{Ru}_{x} \mathrm{O}_{12}, 1050$ ${ }^{\circ} \mathrm{C}$ for $48 \mathrm{~h}$ for $\mathrm{CaCu}_{3-y} \mathrm{Mn}_{y} \mathrm{Ru}_{4} \mathrm{O}_{12}$. The $\mathrm{CuO}$ flux in the latter was removed by $1 \mathrm{~N} \mathrm{HCl}$. The product was finely ground, pressed into a pellet, and sintered in air at $1000-1050{ }^{\circ} \mathrm{C}$ for $20 \mathrm{~h}$ for $\mathrm{CaCu}_{3} \mathrm{Ti}_{4-x} \mathrm{Ru}_{x} \mathrm{O}_{12}, 1050$ ${ }^{\circ} \mathrm{C}$ for $24 \mathrm{~h}$ for $\mathrm{CaCu}_{3-y} \mathrm{Mn}_{y} \mathrm{Ru}_{4} \mathrm{O}_{12}$.

The X-ray diffraction was measured using a standard diffractometer with $\mathrm{Cu} \mathrm{K}_{\alpha}$ radiation as an X-ray source in the $\theta-2 \theta$ scan mode. The susceptibility was measured from 5 to $300 \mathrm{~K}$ by a commercial Superconducting Quantum Interference Device (SQUID, Quantum Design MPMS) in $1 \mathrm{~T}$. The specific heat was measured using a standard relaxation method from 2 to $60 \mathrm{~K}$. The resistivity was measured by the four-probe method from 4.2 
to $300 \mathrm{~K}$ in a liquid $\mathrm{He}$ cryostat. For $\mathrm{CaCu}_{3} \mathrm{Ru}_{4} \mathrm{O}_{12}$, we extended the measurement down to $0.3 \mathrm{~K}$ using a ${ }^{3} \mathrm{He}$ cryostat. but did not find any indication of superconductivity. The thermopower was measured using a steadystate technique from 4.2 to $300 \mathrm{~K}$ in a liquid He cryostat. A temperature gradient of $0.5 \mathrm{~K} / \mathrm{mm}$ was generated by a small resistive heater pasted on one edge of a sample, and was monitored by a differential thermocouple made of copper-constantan. The thermopower of the voltage leads was carefully subtracted.

\section{Results and Discussion}

Figure 1(a) shows the crystal structure of $\mathrm{CaCu}_{3} \mathrm{Ru}_{4} \mathrm{O}_{12}$, which is the $\mathrm{AC}_{3} \mathrm{~B}_{4} \mathrm{O}_{12}$ type structure with $\mathrm{Cu}$ located at the $\mathrm{C}$ site. Since $\mathrm{Cu}^{2+}$ is a small ion, the $\mathrm{RuO}_{6}$ octahedra are highly canted to make the lattice parameter smaller than that of $\mathrm{CaRuO}_{3}$ or $\mathrm{SrRuO}_{3}$. Another interesting feature is that the $\mathrm{Cu}-\mathrm{O}$ distance $(1.94 \AA)$ is as short as the $\mathrm{Ru}-\mathrm{O}$ distance $(1.98$ $\AA) .{ }^{15} \mathrm{Cu}$ is surrounded with four oxygens that are shared with the $\mathrm{RuO}_{6}$ octahedra, and thus we expect a strong hybridization between $\mathrm{Cu} 3 \mathrm{~d}$ and $\mathrm{O} 2 \mathrm{p}$ and between $\mathrm{Ru} 4 \mathrm{~d}$ and $\mathrm{O} 2 \mathrm{p}$, through which $\mathrm{Ru} 4 \mathrm{~d}$ can interact with $\mathrm{Cu} 3 \mathrm{~d}$. As is shown in Fig. 1 (b), the X-ray diffraction pattern of $\mathrm{CaCu}_{3} \mathrm{Ru}_{4} \mathrm{O}_{12}$ is fully indexed as the $\mathrm{AC}_{3} \mathrm{~B}_{4} \mathrm{O}_{12}$ structure. ${ }^{16}$ Other samples are also fully indexed on the structure reported in the literature ${ }^{3,16}$ except for $5 \% \mathrm{RuO}_{2}$ impurity in $\mathrm{CaCu}_{3} \mathrm{Ti}_{2.5} \mathrm{Ru}_{1.5} \mathrm{O}_{12}$.

Figure 2 (a) shows the susceptibility of $\mathrm{CaCu}_{3} \mathrm{Ti}_{4-x} \mathrm{Ru}_{x} \mathrm{O}_{12}$. We have found that the hightemperature data are well fitted with the expression $\chi(T)=\chi_{p}+\chi_{l o c}(T)$, where $\chi_{p}$ is the Pauli paramagnetic susceptibility, and $\chi_{l o c}$ is the Curie-Weiss-type susceptibility $\chi_{l o c}(T)=C /\left(T+\theta_{W}\right)(C$ is the Curie constant, and $\theta_{W}$ is the Weiss temperature). Figure 2

(a)
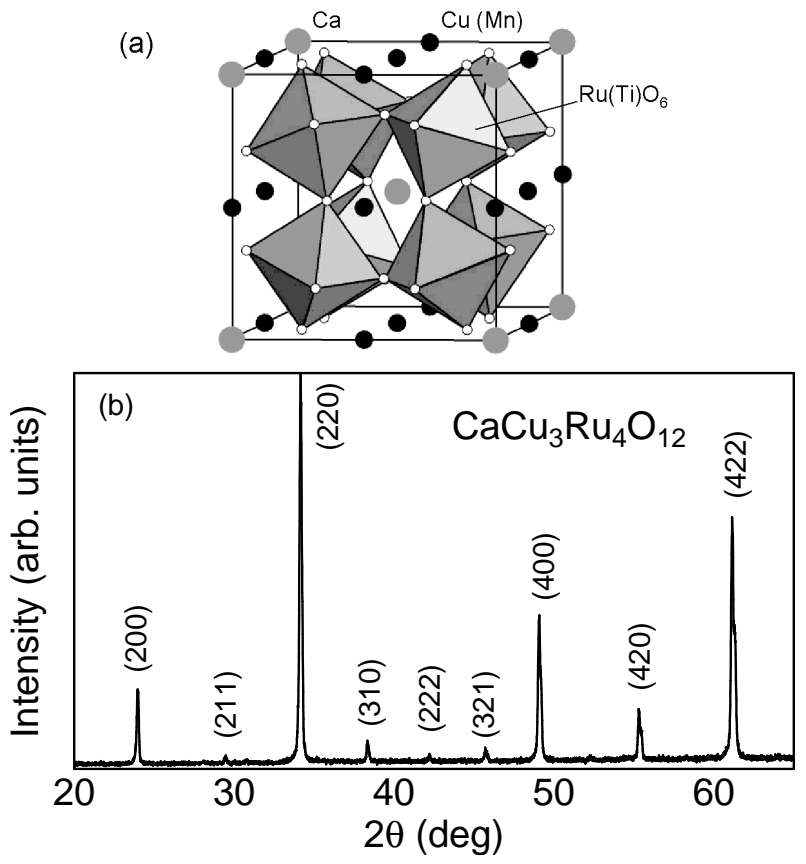

Fig. 1. (a) Crystal structure and (b) X-ray diffraction pattern of $\mathrm{CaCu}_{3} \mathrm{Ru}_{4} \mathrm{O}_{12}$.
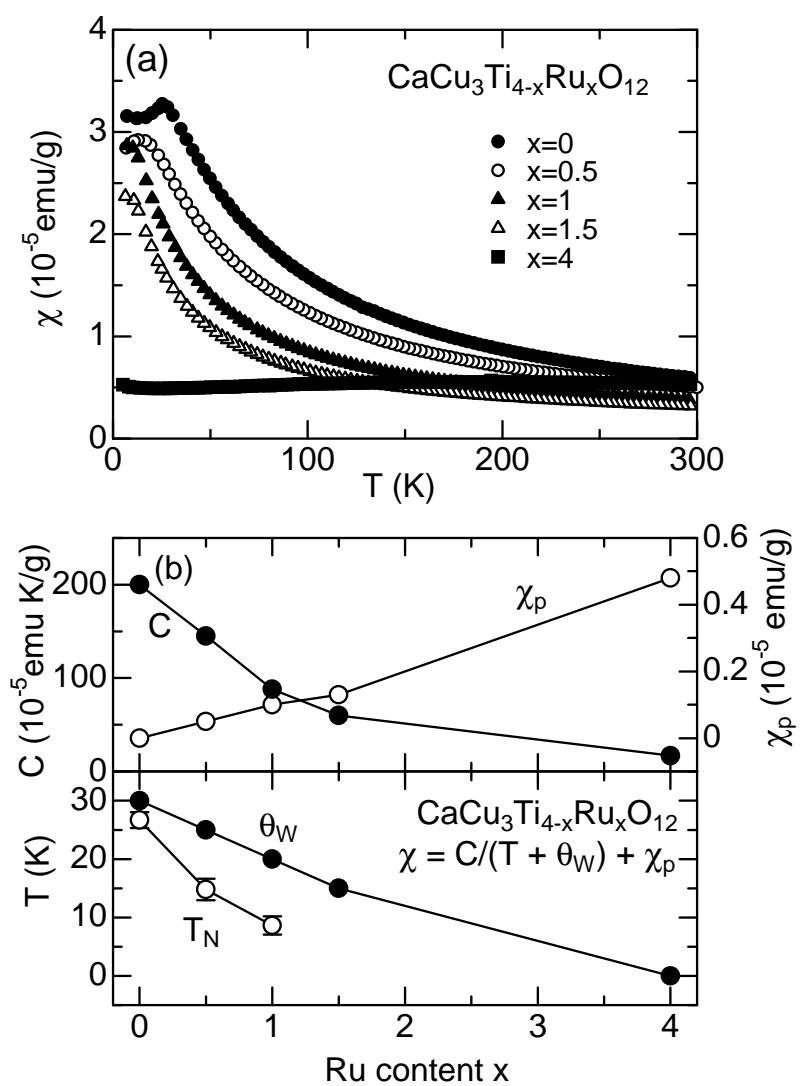

Fig. 2. (a) The magnetic susceptibility of $\mathrm{CaCu}_{3} \mathrm{Ti}_{4-x} \mathrm{Ru}_{x} \mathrm{O}_{12}$ ( $x=0,0.5,1,1.5$ and 4$)$ and (b) the $x$ dependences of the Curie constant $(C)$, the Pauli paramagnetic susceptibility $\left(\chi_{p}\right)$, the Weiss temperature $\left(\theta_{W}\right)$ and the Neel temperature $\left(T_{N}\right)$.

(b) shows the parameters of $C, \chi_{p}$ and $\theta_{W} . C$ for $x=0$ is $2 \times 10^{-3} \mathrm{emu} \mathrm{K} / \mathrm{g}$, which corresponds to $1.3 \mu_{B} / \mathrm{Cu}$. This indicates that $\mathrm{Cu}^{2+}$ for $x=0$ acts as a local spin moment of $S=1 / 2$. With increasing $x, C$ rapidly decreases down to $6 \times 10^{-4} \mathrm{emu} \mathrm{K} / \mathrm{g}\left(0.4 \mu_{B} / \mathrm{Cu}\right)$ for $x=1.5$, and instead $\chi_{p}$ linearly increases. An important feature is that the susceptibility for all the samples seems to merge into a single curve at high temperatures, which suggests that the sum of the contributions of $\chi_{l o c}$ and $\chi_{p}$ is conserved. This strongly suggests that the localized moments on $\mathrm{Cu}^{2+}$ becomes itinerant with increasing $x . \chi$ of $x=4$ was fitted only above $200 \mathrm{~K}$, where $C$ is $1.7 \times 10^{-4} \mathrm{emu} \mathrm{K} / \mathrm{g}\left(0.1 \mu_{B} / \mathrm{Cu}\right)$. It weakly depends on $T$ below $200 \mathrm{~K}$, which will be discussed in the next paragraph. $\theta_{W}$ and the Neel temperature $T_{N}$ for $x=0$ are 30 and $27 \mathrm{~K}$, respectively, which is consistent with the previous data. ${ }^{6} T_{N}$ decreases with $x$ and disappears near $x=2$, which is much faster than the temperatures expected from the dilution effect.

As mentioned earlier, the microscopic mechanism of the delocalization of the $\mathrm{Cu}^{2+}$ moment seen in Fig. 2 was not yet understood. We propose that the localized $\mathrm{Cu}^{2+}$ moment starts to be itinerant through the Kondo coupling with $\mathrm{Ru} \mathrm{4d}$, and finally forms a heavy-fermion state. Here we will show convincing evidence for the heavy-fermion state of $\mathrm{CaCu}_{3} \mathrm{Ru}_{4} \mathrm{O}_{12}$. First, $\mathrm{CaCu}_{3} \mathrm{Ru}_{4} \mathrm{O}_{12}$ shows a typical susceptibility of heavy-fermion metals. As is shown in Fig. 3 (a), $\chi$ of 

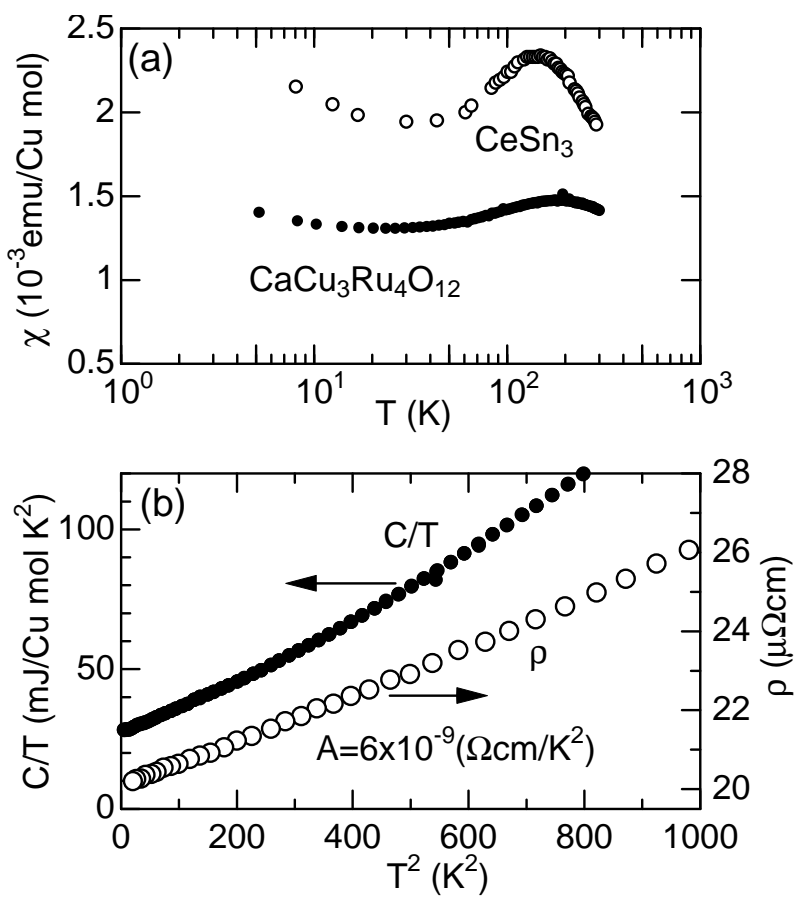

Fig. 3. (a) The susceptibility $\chi$ and (b) the specific heat $(C)$ and the resistivity $\rho$ of $\mathrm{CaCu}_{3} \mathrm{Ru}_{4} \mathrm{O}_{12}$. Note that $\chi$ of $\mathrm{CeSn}_{3}$ is plotted in a unit of emu/Ce mol. ${ }^{17}$

$\mathrm{CaCu}_{3} \mathrm{Ru}_{4} \mathrm{O}_{12}$ quite resembles that of $\mathrm{CeSn}_{3},{ }^{17}$ a typical heavy-fermion metal. A value of $1.4 \times 10^{-3} \mathrm{emu} / \mathrm{Cu} \mathrm{mol}$ is two orders of magnitude larger than the value of free electrons, and a peak at $200 \mathrm{~K}$ is an indication of the Kondo resonance. These results strongly indicate that the $\mathrm{Ru} 4 \mathrm{~d}$ electron interacts with the localized $\mathrm{Cu}$ moment to make a heavy-fermion state below $200 \mathrm{~K}$. The second piece of the evidence is a large electron specific heat. Figure $3(\mathrm{~b})$ shows the specific heat of $\mathrm{CaCu}_{3} \mathrm{Ru}_{4} \mathrm{O}_{12}$. The electron specific heat coefficient $(\gamma)$ is observed to be $28 \mathrm{~mJ} / \mathrm{Cu}$ molK $^{2}$ that is about 20-30 times larger than the value of free electrons. The Willson ratio $R_{W} \equiv \pi^{2} k_{B}^{2} \chi_{p} / 3 \mu_{B}^{2} \gamma$ is 3.8 , which is in an excellent agreement with other heavyfermion compounds. Thirdly, the resistivity exhibits typical features of heavy fermion metals. As shown in Fig. 3(b), the resistivity $(\rho)$ of $\mathrm{CaCu}_{3} \mathrm{Ru}_{4} \mathrm{O}_{12}$ is plotted as a function of $T^{2}$, which clearly shows the relation of $\rho=A T^{2}+\rho_{0}$ as is expected in the Fermi liquid. The coefficient $A$ is evaluated to be $6 \times 10^{-9} \Omega \mathrm{cm} / \mathrm{K}^{2}$, which satisfies the Kadowaki-Woods relation: $A / \gamma^{2}$ is nearly the same value as that for heavy-fermion metals.

We would like to mention some novelties of the heavyfermion state in $\mathrm{CaCu}_{3} \mathrm{Ru}_{4} \mathrm{O}_{12}$. First of all, this is the first compound in which $\mathrm{Cu}^{2+}\left(3 d^{9}\right)$ behaves like $\mathrm{Ce}^{3+}$ $\left(4 f^{1}\right)$ to make conduction electrons heavy. This comes from the peculiar structure that $\mathrm{RuO}_{2}$ octahedra and the $\mathrm{Cu}-\mathrm{O}$ placket are connected in a edge-shared manner. Second, this can be regarded as a conductive perovskite in which the A site is responsible for electric conduction. This is so rare that $\mathrm{BiNiO}_{3}$ would be the only one example ever reported, ${ }^{18}$ which is insulating at low temperatures. Thirdly, the conduction electrons are $\mathrm{Ru}$ $4 \mathrm{~d}$, which can be also magnetic. As is well known, the

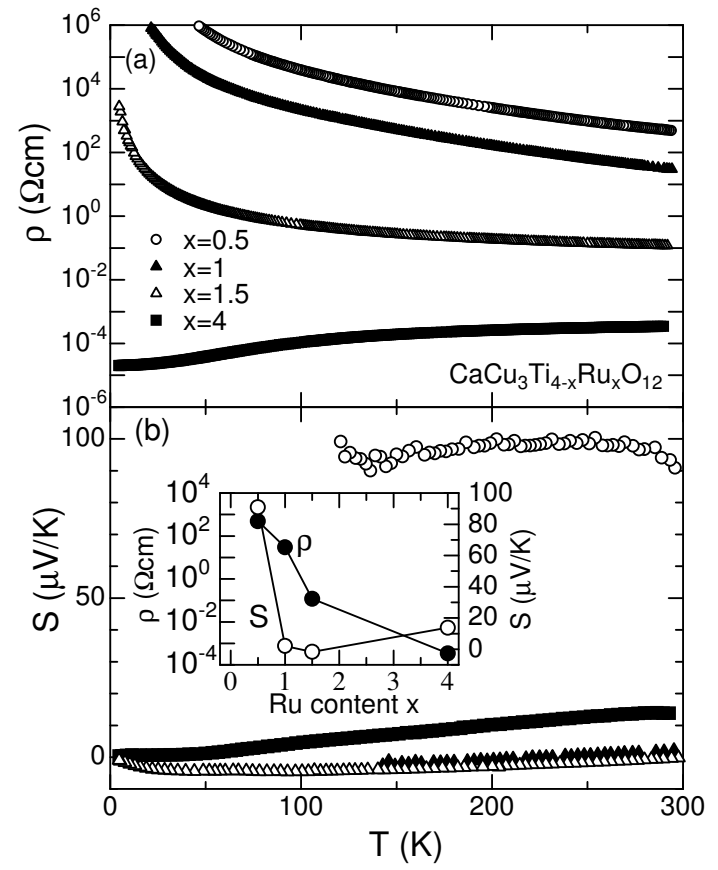

Fig. 4. (a) The resistivity $\rho$, (b) the thermopower $S$ of $\mathrm{CaCu}_{3} \mathrm{Ti}_{4-x} \mathrm{Ru}_{x} \mathrm{O}_{12}(x=0,0.5,1,1.5$ and 4$)$. The inset: the $x$ dependence of $\rho$ and $S$ at $300 \mathrm{~K}$.

perovskite oxide $\mathrm{SrRuO}_{3}$ is a ferromagnetic metal. It is thus surprising that the ground state of $\mathrm{CaCu}_{3} \mathrm{Ru}_{4} \mathrm{O}_{12}$ is "nonmagnetic", though almost all cations are magnetic.

Figure 4(a) shows $\rho$ of $\mathrm{CaCu}_{3} \mathrm{Ti}_{4-x} \mathrm{Ru}_{x} \mathrm{O}_{12}$, which changes from $10^{3}(x=0)$ to $10^{-4} \Omega \mathrm{cm}(x=4)$ at 300 $\mathrm{K}$. The temperature dependence also changes from insulating to metallic, and an insulator-metal transition occurs between $x=1.5$ and $x=4$. Figure $4(\mathrm{~b})$ shows the thermopower $(S)$ of $\mathrm{CaCu}_{3} \mathrm{Ti}_{4-x} \mathrm{Ru}_{x} \mathrm{O}_{12}$. Most unexpectedly, $S$ suddenly decreases from $100 \mu \mathrm{V} / \mathrm{K}$ for $x=0.5$ to a few $\mu \mathrm{V} / \mathrm{K}$ for $x=1.0$, whereas $\rho$ for $x=1.0$ is still high. Since the small thermopower is a hallmark of a metal, this indicates that the delocalization of the $3 \mathrm{~d}$ holes on $\mathrm{Cu}^{2+}$, i.e., the Kondo coupling with the $\mathrm{Ru}$ $4 d$ electron, already occurs at $x=1$. We infer from the Curie constant in Fig. 2(b) that a half of the 3d holes are coupled with $\mathrm{Ru} 4 \mathrm{~d}$. Although the Kondo coupling between $\mathrm{Ru} 4 \mathrm{~d}$ and $\mathrm{Cu} 3 \mathrm{~d}$ exists, the conduction path is seriously segmentized at $x=1$. This is the reason of the high resistivity for $x=1$. In contrast, the thermopower is a direct probe for the entropy per conductive carriers, it is less affected by the insulating region in the sample. In fact, $E_{F}=1.4 \mathrm{eV}$ estimated for $50 \%$ of $\mathrm{Cu}^{2+}$ gives the diffusive term of the thermopower $k_{B}^{2} T / e E_{F}=1 \mu \mathrm{V} / \mathrm{K}$ at $300 \mathrm{~K}$, which is consistent with the observed data. We further note that the thermopower of $\mathrm{CaCu}_{3} \mathrm{Ru}_{4} \mathrm{O}_{12}$ is similar to that of $\mathrm{CeSn}_{3},{ }^{19}$ which is consistent with the data in Fig. 2.

Figure 5(a) shows $\rho$ of $\mathrm{CaCu}_{3-y} \mathrm{Mn}_{y} \mathrm{Ru}_{4} \mathrm{O}_{12} . \rho$ systematically increases with $y$, which further supports that the $\mathrm{Cu}$ site contributes to the conduction. $\rho$ for the $\mathrm{Mn}$ doped samples is understood in terms of the sum of $\rho$ for $y=0$ and the impurity-scattering term induced by Mn. The impurity scattering is usually independent of 


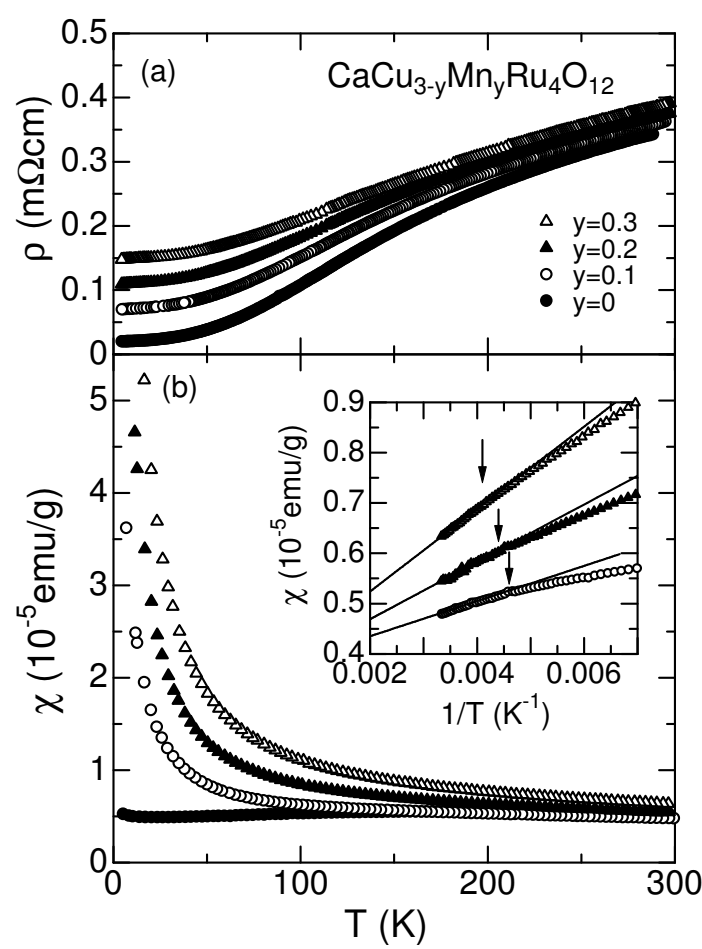

Fig. 5. (a) The resistivity $\rho$ and (b) the susceptibility $\chi$ of $\mathrm{CaCu}_{3-y} \mathrm{Mn}_{y} \mathrm{Ru}_{4} \mathrm{O}_{12}(y=0,0.1,0.2$ and 0.3$)$.

temperature, and the resistivity of an impurity-doped sample is shifted upward in parallel to the resistivity of a pure sample. However, this is not the case. The residual resistivity at $4 \mathrm{~K}$ is roughly proportional to the $\mathrm{Mn}$ content, as is seen in the impurity scattering of a conventional metal. On the other hand, the resistivity is nearly independent of $y$ at room temperature. This can be also understood from the heavy-fermion scenario. At room temperature (above the Kondo temperature), $\mathrm{Mn}^{3+}$ and $\mathrm{Cu}^{2+}$ seem similar magnetic scatterers to the conduction electrons. In contrast, the $\mathrm{Cu} 3 \mathrm{~d}$ moments coherently move with the conduction electrons below the Kondo temperature, where only the $\mathrm{Mn}^{3+}$ remains as a scatterer.

Figure 5(b) shows $\chi$ of $\mathrm{CaCu}_{3-y} \mathrm{Mn}_{y} \mathrm{Ru}_{4} \mathrm{O}_{12}$, which obeys the Curie law for $y>0$. The Curie constant for $y>0$ corresponds to $2 \mu_{B} / \mathrm{Mn}$, which is a half of the value expected from $\mathrm{Mn}^{3+}(S=2)$. We do not understand the reason of the unusual small moment of $\mathrm{Mn}^{3+}$. One possibility is that $\mathrm{Mn}^{3+}$ is antiferromagnetically coupled with the neighboring $\mathrm{Cu}^{2+}$. As shown in the inset, $\chi$ exhibits a kink near $200 \mathrm{~K}$ which means that the Kondo coupling remains against the Mn doping. This is consistent with the metallic nature of the Mn-doped samples.

\section{Summary}

The susceptibility, electron specific heat, resistivity and thermopower of $\mathrm{CaCu}_{3} \mathrm{Ru}_{4} \mathrm{O}_{12}$ are consistently and quantitatively understood as those of a heavy-fermion metal with the Kondo temperature of $200 \mathrm{~K}$. This comes from the interaction between $\mathrm{Cu} 3 \mathrm{~d}$ and $\mathrm{Ru} 4 \mathrm{~d}$ electrons.
The former corresponds to the localized $f$ electron, and the latter corresponds to the conduction electron. In this sense, $\mathrm{CaCu}_{3} \mathrm{Ru}_{4} \mathrm{O}_{12}$ is a complete analogue to the $\mathrm{f}$ electron heavy fermion metal. We have further found that a insulator-metal transition in $\mathrm{CaCu}_{3} \mathrm{Ti}_{4-x} \mathrm{Ru}_{x} \mathrm{O}_{12}$, which can be regarded as a transition from magnetic insulator to heavy fermion state, through which the hole on $\mathrm{Cu}^{2+}$ starts to be itinerant by the help of the Kondo coupling with $\mathrm{Ru} 4 \mathrm{~d}$.

Before completion of the present manuscript, we found the preprint of Ramirez et al. on the preprint archives (cond-mat/0403742). They discussed the itinerancy of the $\mathrm{Cu}^{2+}$ moment in $\mathrm{LaCu}_{3} \mathrm{Ti}_{4-x} \mathrm{Ru}_{x} \mathrm{O}_{12}$. However, they did not show susceptibility data of $\mathrm{CaCu}_{3} \mathrm{Ru}_{4} \mathrm{O}_{12}$, and did not mention the heavy-fermion state either.

\section{Acknowledgments}

The authors would like to thank Shintaro Ishiwata for fruitful discussion on $\mathrm{BiNiO}_{3}$. This work was partially supported by Grant-in-Aid for JSPS Fellows.

1) Landolt-Börnstein, Magnetic Properties of Non-magnetic Inorganic Compounds Based on Transition Elements, Group III, Condensed Matter, Volume 27/F1 $\beta$ (Springer, Berlin), p. 280.

2) M. Marezio, P. D. Dernier, J. Chenavas, and J. C. Joubert: J. Solid State Chem. 6 (1973) 16.

3) B. Bochu, M. N. Deschizeaux, J. C. Joubert, A. Collomb, J. Chenavas, and M. Marezio: J. Solid State Chem. 29 (1979) 291.

4) M. A. Subramanian, D. Li, N. Duan, B. A. Reisner, and A. W. Sleight: J. Solid State Chem 151 (2000) 323.

5) C. C. Homes, T. Vogt, S. M. Shapiro, S. Wakimoto, and A. P. Ramirez: Science 293 (2001) 673.

6) A. Koitzsch, G. Blumberg, A. Gozar, B. Dennis, A. P. Ramirez, S. Trebst, and S. Wakimoto: Phys. Rev. B65 (2002) 052406.

7) L. He, J. B. Neaton, M. H. Cohen, D. Vanderbilt, and C. C. Homes: Phys. Rev. B65 (2002) 214112.

8) W. Kobayashi, and I. Terasaki: Physica B 329-333 (2003) 771.

9) Z. Zeng, M. Greenblatt, M. A. Subramanian, and M. Croft: Phys. Rev. Lett. 82 (1999) 3164.

10) R. Przenioslo, I. Sosnowska, E. Suard, A. Hewat, and A. N. Fitch: J. Phys.: Cndens. Matter 14 (2002) 5747.

11) W. Kobayashi, I. Terasaki, M. Mikami, and R. Funahashi: J. Phys. Soc. Jpn. 73 (2004) 523.

12) W. Kobayashi, I. Terasaki, M. Mikami, R. Funahashi, T. Nomura, and T. Katsufuji: J. Appl. Phys. (in press).

13) S. Kondo, D. C. Johnston, C. A. Swenson, F. Borsa, A. V. Mahajan, L. L. Miller, T. Gu, A. I. Goldman, M. B. Maple, D. A. Gajewski, E. J. Freeman, N. R. Dilley, R. P. Dickey, J. Merrin, K. Kojima, G. M. Luke, Y. J. Uemura, O. Chmaissem, and J. D. Jorgensen: Phys. Rev. Lett. 78 (1997) 3729.

14) M. A. Subramanian, and A. W. Sleight: J. Solid State Chem. $167(2002) 126$

15) S. G. Ebbinghaus, A. Weidenkaff, and R. J. Cava: Solid State Sciences 4 (2002) 347.

16) M. Labeau, B. Bochu, J. C. Joubert, and J. Chenavas: J. Solid State Chem. 33 (1980) 257

17) T.-W. E. Tsang, K. A. Gschneidner, Jr., O. D. McMasters, R. J. Stierman, and S. K. Dhar: Phys. Rev. B 29 (1984) 4185.

18) S. Ishiwata, M. Azuma, M. Takano, E. Nishibori, M. Takata and M. Sakata, K. Kato: J. Mater. Chem. 12 (2002) 3733.

19) G. D. Mahan: Solid State Phys. 51 (1998) 81. 